\title{
THE METROLOGY AND THE BIM APPROACH: A NEW COGNITIVE PARADIGM ABOUT THE ANCIENT CONSTRUCTION
}

\author{
P. Fiamma \\ Department DESTeC, School of Engineering, University of Pisa, Italia - paolo.fiamma@ing.unipi.it \\ Commission II
}

KEY WORDS: ancient construction, BIM level, maintenance, methodology, technical component modeling

\begin{abstract}
:
Nowadays, some important issues in the BIM field and research are still open, and are not deeply known and really understood yet by all the BIM users and approaches; unfortunately, this critical situation implies, often, incorrect approaches and ineffective applications, especially using BIM for existing historical building, where the object oriented approach has so many limitations. In fact, the current laser scanning technology can detect just a cloud of points that is considered "non-intelligent" according to the BIM method and meaning. The paper presents an important case study: the Cathedral of Piazza dei Miracoli (Miracles Square) in Pisa. The method we propose consists of an innovative procedure combining in a two-way manner the correspondence levels between metrology and ontology of the constructive components. The paper proves that is not important to obtain the best possible level of modeling performance. We need a specific BIM approach, for "a specific building", according with "a specific project". We believe that it is precisely in this capacity of matching between metrological and constructive knowledge (mediated by computer graphics technology) that it is possible to identify the response to an important programmatic indication in the BIM field: "how much BIM?". This sentence was explained by Charles Eastman (recognized worldwide as the father of BIM) during his "lectio magistralis" at the Master BIM of the University of Pisa (www.unibim.it). We guess this is the way to be free from any pre-established intervention standards, and so to be adapting to a specific construction for a specific intervention's level using specific resources.
\end{abstract}

\section{INTRODUCTION}

Using a method like BIM does not seem to be the most suitable procedure for a project in a historical and monumental context. There are two categories of reasons: the BIM is based on objectoriented ontology and to date there is no possibility of having the existing scanning procedures able to automatically give this ontology. In addition, a historical and monumental work is by nature unique, so not really suited to methods based on standardized elements. These are two technical observations that cannot be considered incorrect. However, there is a field of research called HBIM in which there are many examples of BIM approaches to cultural heritage. The present contribution therefore presents a precise technical-scientific position, even if unpopular, by those who know and have used the BIM method for many years. Nowadays, experimenting with BIM for cultural heritage is correct, thinking for sure that we can use BIM for cultural heritage is not correct. I therefore propose to use a very important approach that we can express with a question: how much BIM? This sentence was explained by Charles Eastman (recognized worldwide as the father of BIM) during his "lectio magistralis" at the Master BIM of the University of Pisa (www.unibim.it). We guess this is the way to be free from any pre-established intervention standards, and so to be adapting to a specific construction for a specific intervention's level using specific resources.

\section{CASE OF STUDY}

\subsection{Critical aspects}

The Opera Primaziale Pisana (OPA) is the Institution that administers the Piazza dei Miracoli (and is a partner of the Master BIM of the University of Pisa). A few years ago the OPA asked our research group to present at the conference
"European Cathedrals New Technologies", a research session about BIM for Cathedrals. The intuition was born from the need to experiment with new methods for the approach of the maintenance of the historical monumental heritage. Some aspects emerged immediately:

- the complexity of the realization of a digital model of a Cathedral, according to the BIM method.

- the need to intersect the knowledge of BIM with other disciplines.

A research process has begun which - in recent years - has led to important results regarding the need to identify a specific method for using BIM for the Monumental Heritage. It is useful to remember that various approaches have been examined that can be traced back to two concepts of modeling the characteristics of an Opera. We will be able to define a first approach as a reconstruction of the work by means of a model taken from photographs and measurements; and a second approach based on 3D laser scans. It is important to remember that these two approaches are unrelated to the BIM method. The BIM model needs from the availability of 3D oriented objects. How to obtain a three-dimensional oriented object becomes a very important point to evaluate the effectiveness of the application of BIM in a monumental context. The two procedures mentioned lead to very different results especially for an audience of people who are not BIM experts. In fact, they differ in terms of visual resolution of the model. It should be remembered that customers generally speaking belong to the category of people who are not only experts in BIM but also in computer graphics. It is therefore very easy for misunderstandings to arise in this phase of the procedure. Today everyone has the opportunity to watch movies in video games with digital effects. It is taken for granted that this is the level at which technology can arrive and it is taken for granted that it can be so for anyone who produces a 3D digital model and for every 3D digital model. In our experience, we often find people 
who confuse the level of technology that is needed in computer graphics, for example in entertainment, with the level of technology that must be required in applications in other fields of knowledge. Within the Monumental Heritage, the risk of a misunderstanding on the necessity of the level of definition is very high because it is a matter of amazing Opera (and not, for example, a matter of new buildings). A 3D model based on the combination of photogrammetry and direct measurement; or a 3D model based on a laser scan, are two models that involve different implementation processes and lead to different results. The costs of the two procedures mentioned can also be very different: and this is a fact that customers understand very well, although for them it often appears a paradox that a laser scan, which implies a reduced application of the employees compared to the photogrammetric applications, allows you to get results with much greater visual definition. The higher staff cost is a worse result in terms of final display. It is therefore necessary to communicate clearly that the choice of the two procedures should not be taken with respect to a final result in terms of model visualization. The higher cost of personnel corresponds not to a greater definition of the model but a greater constructive knowledge of the artifact. Very often the realization of a BIM model of a monumental work makes it clear that the work itself is not totally and completely known by the Institution that owns that building. To make a BIM model you must first identify and then know all the elements of the Opera and their attributes. For the greatness of the Monumental Works many minor elements cannot be known and recognized except through exploration and direct contact; and for the stratification of historical events over the centuries, very often, a lot of information, related to them, had been lost. It is not important the level of detail of the model but the type of detail that interest. For a constructive detail a laser scan may not be enough (and often even an image). To understand the constructive detail, a direct survey and measurement of the element is required. For a pictorial or decorative detail, an image or a high-resolution scan may be sufficient. What kind of BIM model you need to realize depends, in our opinion, on the purpose that that model has. Depending on the purpose, a certain level of visual definition will be required; and therefore a specific procedure that identifies ways of capturing measurements, images, details, information, etc. In our experience, very often, a BIM model designed for reasons of construction maintenance does not need to have a high visual definition, such as that of a 3D model used for restoration work.

\subsection{Procedure}

In order to obtain a correct the experimentation it is important to first set up a procedure plan. In the plan it is necessary to make explicit all the passages of method and merit: 1 . Resource analysis. 2. Objectives. 3. Plan of the phases and of the actors.

1. Resources:

1.1 - People

1.2 - Tools

1.3 - Time

2. Objectives

2.1 - Identification of requirements for a maintenance plan according to the BIM approach

2.2 - The maintenance plan must be performed by third parties 3. Phases and actors

3.1 - Group survey phase with participants of the HBIM module

3.2 - Group return phase of the transept model

3.3 - Identification phase for subgroups of the example objects

3.4 - Modeling phase by sub-group of the sample object (that group was composed by Architects Lucia Conte, Fabrizio Biundo, Edoardo Ghelardi an Engineer Oscar Vignone)

3.5 - Assignment of the characteristics of the maintenance plan. 3.6 - Insertion phase of the model oriented in the general model of the Transept

3.7 - Criteria for checking the maintenance plan

\subsection{Experimentation}

In our Master BIM program, a special teaching module explains the themes of digital photogrammetry that deals with the phase of creation of the point cloud model. The next module introduces the TLS (Terrestrial Laser Scanner) capture methodology succinctly; and then the themes of information modeling for the existing are addressed with the BIM method. In the Figure 1 it is possible to see the group of HBIM module and the transept of the Cathedral under maintenance. In the Figure 2 a internal view of the Transept and the preparation of the laser scan phase under managed by Ing. Simone Garagnani.

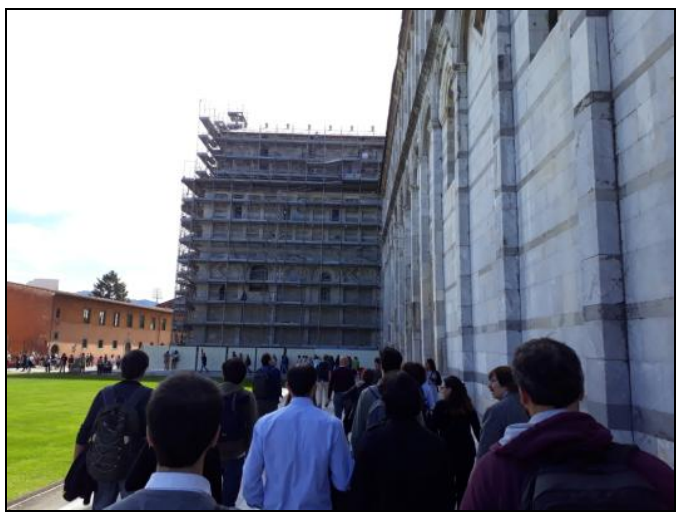

Figure 1. External view of the Transept of the Cathedral

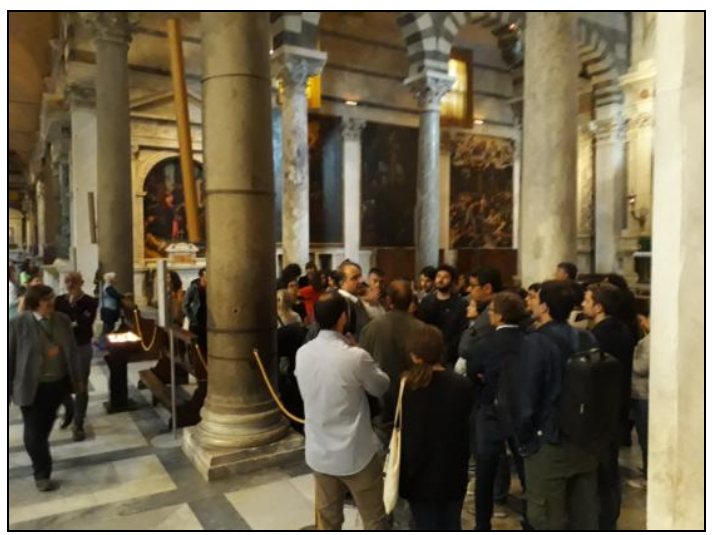

Figure 2. Preparation of the laser scan phase into the Transept

From the point cloud, we continue with the "scan to BIM" phase, which is relevant to the methodology and software tools used to achieve modeling (models at various levels of detail) and segmentation. A critical approach to comparison criteria relevant to HBIM processes is proposed. Abstractions have been obtained from the point cloud, obtained by recording multiple scan stations. CPR and RCS to enable successful import into the BIM modeling environment used (Autodesk Revit) by registering in Faro Scene, converting to Autodesk ReCap, and then checking cloudCompare. In the Figure 3 some of the views of the Transept obtained from the point cloud. The work focused primarily on parametric modeling from the cloud in Revit, with a focus on semantic components discovered for 
system families and some downloadable families, such as columns. In this sense, the production of clouds with preferably calibrated color would be indicated. The georeference of the relief and the connection via polygonal from classic relief would be another theme to deepen to make the model more complete.
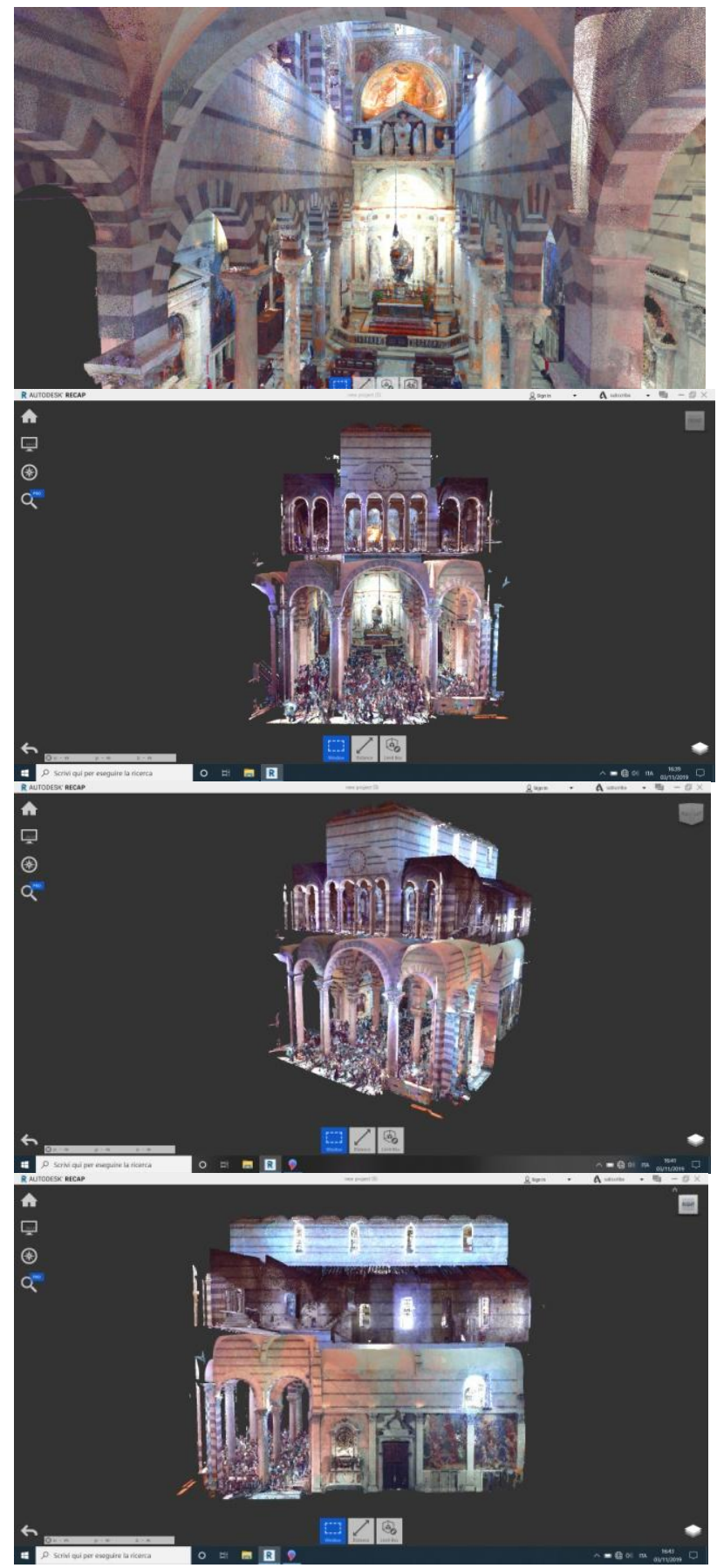

Figure 3. Views of the Transept obtained from the point cloud.

In order to proceed with the experiment, objects considered significant for the possibility of combining construction characteristics and modeling possibilities were identified. An ancient building cannot be read from the construction and architectural point of view as a set of standard components (a column, a truss, a wall ...); we can't automatically obtain their 3D objects oriented models. Each building has its own column, capital, beam or wall that the building's history allowed today to become what they really are; and so different with respect to any other element of another building, although of the same typology and the same age. The choice of a set of constructive objects aims to address the relationship between the parts of a monumental opera and a possible, orthodox and innovative approach, from the point of view BIM combined with a specific level of knowledge and need of maintenance. In order to have a base of examples for the development of the project, tabs have been prepared for the discovered objects, containing technical and historical information.

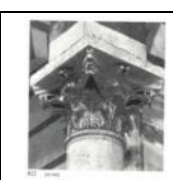

\section{Capitello \\ Corinzio asiatico Inizi del secolo III dopo Cristo \\ Di autore ignoto Caratterizzato da} foglie di acanto spinoso. In marmo delle cave del Proconnesio

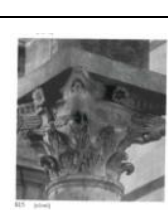

caratterizzato da molli con solcature base della foglia.

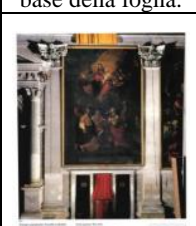

\section{Capitello} composito Inizi del secolo II dopo Cristo Di autore ignoto ha subito riparazioni. È foglie di acanto

\section{Edicola} contenente la Vergine in gloria e Santi $(5,5 \times 3,0 \mathrm{~m})$ Proviene dall'altar maggiore della chiesa di San

Jacopo degli Speronai. Dipinto realizzato da Domenico Cresti detto il Passignano (1559 -1638). Acquistato da "deputati dei parati di San Ranieri". Collocato in Duomo a fine settecento. Delimitato da semicolonne concluse da capitelli sui quali corre un cornicione

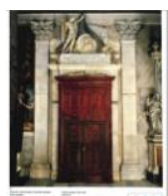

Monumento
dell'arcivescovo
Angelo
Franceschi
ubicato sopra
l'architrave della
porta del SS.

Altare marmoreo dei SS. Maria e Clemente $(6,70 \times 4,2 \times 0,75$ $\mathrm{m}$ circa) Di Stagio Stagi (fine secolo XV Sacramento

Realizzato da Tommaso Masi (artista attivo tra la fine del sec XVIII e l'inizio del VIX) dopo il 1806 su commissione dei nipoti del defunto arcivescovo Zoccolo con iscrizione sopra il quale un bassorilievo raffigurante il prelato

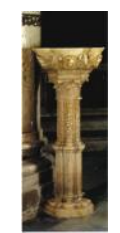

Acquasantiera.

Realizzata nel 1464 da Domenico di Giovanni da Milano. Altezza complessiva dell'acquasantiera $1,305 \mathrm{~m}$, diametro della tazza $58 \mathrm{~cm}$. Pilastro polilobato coronato da quattro serti (Ghirlanda, corona, come ornamento o segno di vittoria), sui quali si erge un capitello caratterizzato da grand foglie di acanto. Tazza di contenimento dell'acqua santa anch'essa polilobata, è caratterizzata da mascheroni e stemmi dell'Opera tra cespi d'acanto.

ra il 1528 ed il 1532 1563). Realizzato

Mensa centrale tra due semicolonne su alti basamenti. Capitelli di coronamento decorati con teste di ammoni. Lesane laterali decorate e arco arricchito da motivi vegetali.

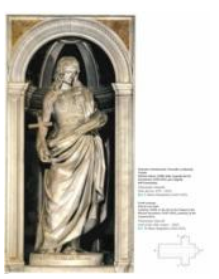
Cappella del SS Sacramento All'interno statia di S. Maria Maddalena in marmo bianco di Carrara $(2,00 \times 0,70 \times 0,40$ circa $)$ Indossa un corsetto allacciato al petto con mantello

Realizzata da Chiarissimo Fancelli tra il 1662 ed il 1625

Le cui iniziali dello cultore sono a sinistra in un lembo della veste

Figure 4. Information sheets of the internal parts of the Transept 


\subsection{Definition of a protocol}

In order to define a protocol to maintenance it was necessary to understand the possible common needs of every parts (3D objects). The two tables in Figure 5 have a particular importance. The first one summary displays the parts to be analyzed, for which the tabs will have to be built. The other table, the second, shows the restoration protocol in an exhaustive way. On two columns, the first, are reported the types of problems that can be encountered in practice, on the third the "Type of Intervention" for each "Type of Problem". The two tables allow us to highlights some proprieties specific for the objects needs of maintenance: every single object oriented model will include text spaces, about the proprieties, that will have to be filled according the phases and the actors, during the maintenance protocol.

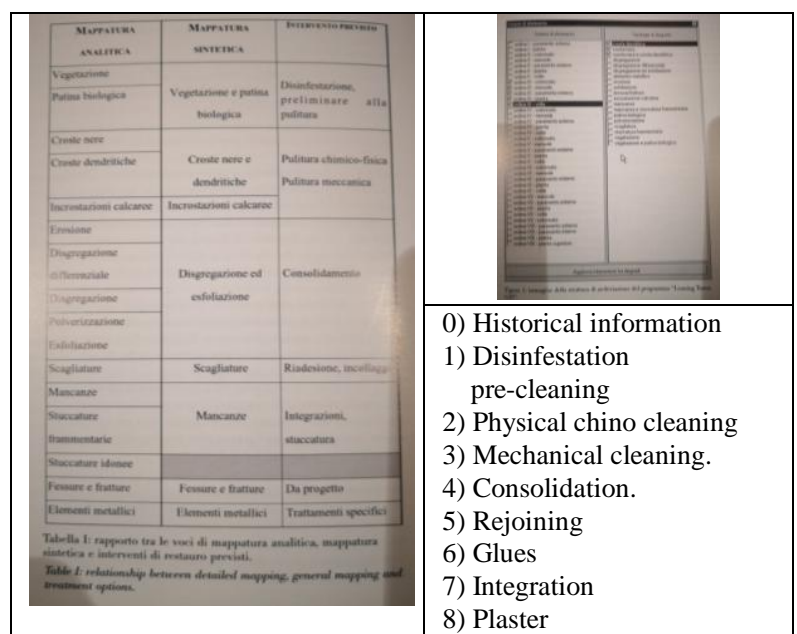

Figure 5. A sample of information system for maintenance

The level of BIM we need is the level that match the possibility to measure and modeled an object in order it present the proprieties written in the table, that are the information we need about that object. Optical metrology and BIM must be combined as two elements that are expression of the knowable of the existing building: these two levels of knowledge are combined by the level of the maintenance of the opera. Ontology of maintenance becomes the metrology level: both are necessary to optimize the level of BIM we need. In the Figure 6, made by the group, there are the $3 \mathrm{D}$ object oriented models made by the group according the procedure we propose.

\section{CONCLUSION}

Today, protecting and maintaining the monumental heritage is a cultural and social necessity that needs to use the most innovative technical resources. In addition, the need to optimize available economic resources is increasingly dramatic in times of economic crisis. The two objectives mentioned are an integral part of the AEC field in Italy, which today is crossed by the novelty of the BIM method. It is therefore natural for everyone to think that there can be a use of BIM also for historical and monumental works. The complexity of the subject, the interdisciplinary nature of the knowledge involved, the need to optimize operational resources, highlights a problem of knowledge and "knowability" of the good that could be entrusted to this method of information modeling. All the reasons cited are not sufficient to consider being able to extend BIM to the historical heritage to obtain the same advantages that it allows for the new design. The limit is not cultural or procedural but technical and one cannot think that it does not exist. The scientific community must continue research in the

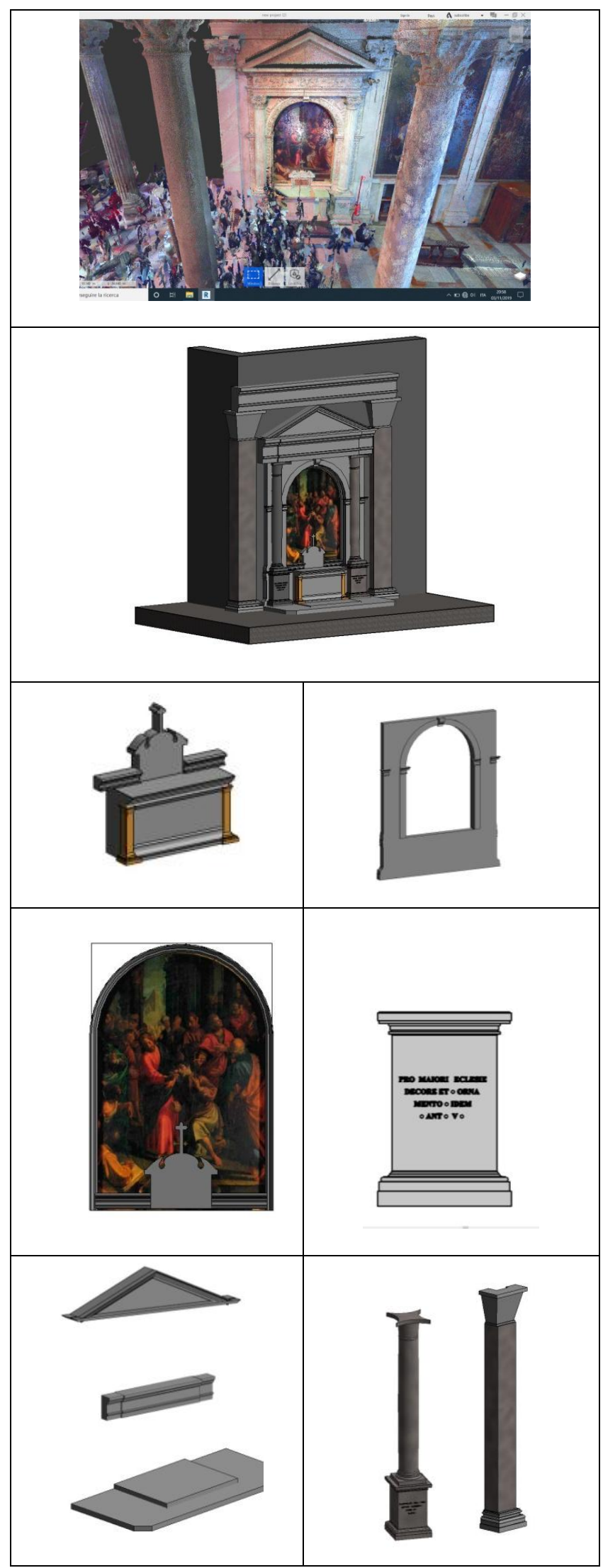

Figure 6. Object oriented models for the maintenance needs 
field of automatic recognition of ontology by the instruments used for the survey. The experimentation on the transept of the Cathedral of Pisa documents that it is possible to use the BIM but it is necessary to understand first what level of use and maintenance is necessary as showed in Figure 7 ( made by the group: Lucia Conte, Fabrizio Biundo, Edoardo Ghelardi Oscar Vignone). We believe that today we cannot ignore a careful measurement of the resources that are used in the procedure for obtaining the model.

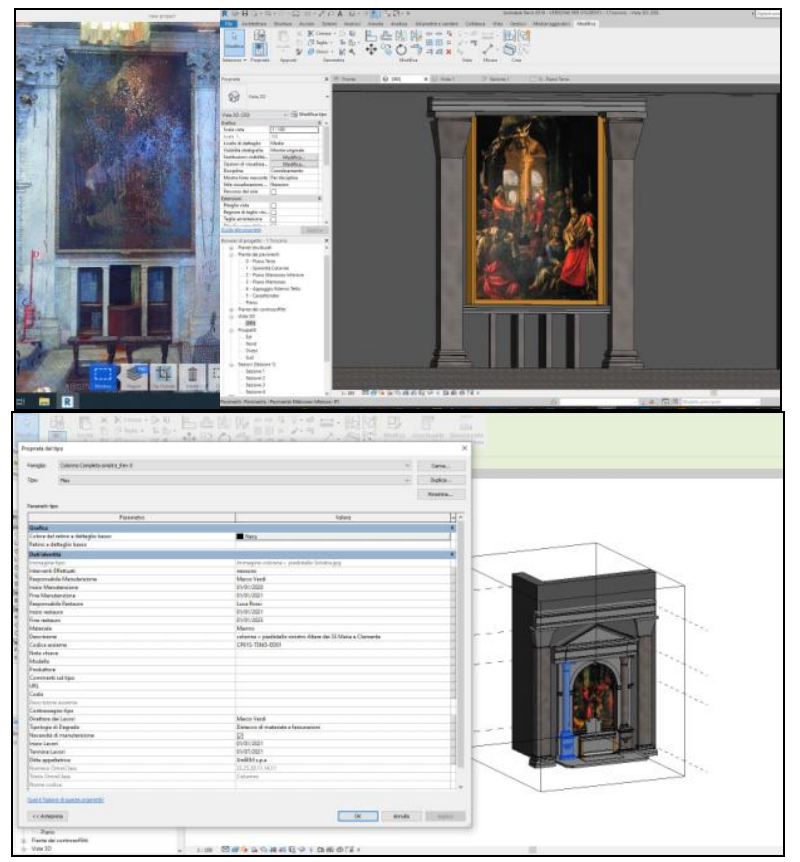

Figure 7 . The modeling according the maintenance program

The investigation for a structural or architectural understanding would also be favored; or the realization of an interactive database of information that has been stratified in the interventions over the centuries or that will have to be programmed. In the logic of the intervention to be carried out, the BIM certainly offers in the ongoing control of the process and in the prevention of possible design and execution errors, indisputable advantages precisely in relation to the importance and value of the works involved, as in the case of Cathedrals. In this sense, it would be possible to derive important advantages from the extension of the BIM to the methods of realization of the support works for the interventions at height. The prefiguration of the temporalization of the construction site phases would be justified by the need to identify precisely the times and methods for suspending access to the public. If the difficulty of having objects oriented, can only be solved by the continuous evolution of technology, already from today, the computational resources $\mathrm{h} / \mathrm{s}$, allow to manage a huge amount of data, documenting the possibility of experimenting also for the Cathedrals, the BIM method where the design model and the operational process are made one-to-one. Getting the first benefits will favor further developments.

\section{REFERENCES}

Arayici Y., Counsell J., Mahdjoubi L., Nagy G.A., Hawas S., Dweidar K., 2017. Heritage Building Information Modelling, Routledge, London, UK. doi.org/10.4324/9781315628011
Azhar S., 2011. Building Information Modeling (BIM): Trends, Benefits, Risks, and Challenges for the AEC Industry. Asce: American Society of Civil Engineers, Vol. 11, Issue 3. DOI: 10.1061/(ASCE)LM.1943-5630.0000127

Chow L., Graham K., Grunt T., Gallant M., Rafeiro, J., Fai S. 2019. The evolution of modelling practices on Canada's parliament hill: an analysis of three significant heritage Building Information Models (HBIM), Int. Arch. Photogramm. Remote Sens. Spatial Inf. Sci., XLII-2/W11, 419-426. DOI: 10.5194/isprs-archives-XLII-2-W11-419-2019

Eastman C.M., 1988. Automatic Composition in Design, Proceedings of the 1988 NSF Grantee Workshop on Design Theory and Methodology.

Fai S., Rafeiro J., 2014. Establishing an Appropriate Level of Detail (LoD) for a Building Information Model (BIM)-West Block, Parliament Hill, Ottawa, Canada. ISPRS Ann. Photogramm. Remote Sens. Spatial Inf. Sci., 1, 123-130. Doi:10.5194/isprsannals-II-5-123-2014

Fiamma P., 2003. Architectural design and digital paradigm from Renaissance models to Digital Architecture, in Proceedings of the Acadia 22 Conference, Indianapolis, USA.

Frampton K., 1995. Studies in Tectonic Culture, MIT Press.

Garagnani, S. 2017. Archaeological Building Information Modeling: beyond scalable representation of architecture and archaeology, in Archeologia e Calcolatori, n. XXVIII.2 - 2017 doi.org/10.19282/AC.28.2.2017.09

Garagnani S., 2013. Building Information Modeling and real world knowledge: a methodological approach to accurate semantic documentation for the built environment, in Digital Heritage 2013 International Congress, Marseille, France.

Ilter D., Ergen E., 2015. BIM for building refurbishment and maintenance: current status and research directions, in: Structural Survey, Vol.33 Is.3, International Journal of Building Pathology and Adaptation. DOI: 10.1108/SS-02-2015-0008

Kolarevic B., 2003. Architecture in the Digital Age: design and manufacturing, Taylor \& Francis, London, UK.

Liston K., Sacks R., Teicholz P., Eastman C. M., 2011. BIM Handbook: A Guide to Building Information Modeling for Owners, Managers, Designers, Engineers and Contractors 2nd Edition, Wiley.

Rua H., Gil A., 2014. Automation in heritage - Parametric and associative design strategies to model inaccessible monuments: The case-study of eighteenth-century Lisbon Águas Livres Aqueduct, in: Digital Applications in Archaeology and Cultural Heritage, Volume 1, Issues 3-4, doi.org / 10.1016 /j.daach. 2014.06.002

Volk R., Stengel J., Schultmann F., 2014. Building Information Modeling (BIM) for existing buildings-Literature review and future needs, in Automation in Construction (38), 109-127. doi.org/10.1016/j.autcon.2013.10.023 